in mind that some reflexions will be absent in the latter.

A. Franks

K. F. HALE

National Physical Laboratory,

Teddington, Middlesex.

'Burgers, W. G., Nature, 189, 741 (1961).

'Lippmann, G., C.R. Acad. Sci., Paris, 112, 274 (1891).

${ }^{3}$ Crawford, B. H., J. Sci. Instr., 31, 333 (1954).

4 N.P.L. Notes on App. Sci., No. 20 (H.M.S.O., London, 1960).

\section{Thermoelectric Power of Gallium}

My recently published measurements of the thermoelectric power of single crystals of gallium ${ }^{1}$ have been followed by a measurement of the thermo. electric power of liquid gallium and by confirmatory calibration runs with lead and copper. During the course of these measurements, it was realized that the sign convention used in the presentation of the earlier results, that quoted by $\mathbf{R}$. Stratton ${ }^{2}$, was inconsistent with some others which had been used in the compilation of results for this work. The sign of the E.M.F. plotted in Fig. 1 and Table 1 of the earlier communication must be reversed to make the results consistent with the convention quoted below that diagram.

Using the convention as printed ${ }^{1}$ and combining the results with the absolute thermoelectric power $\left(Q^{*}\right)$ of copper give the following revised values:

$$
\begin{aligned}
& Q_{\mathrm{Ga}(100)}^{*}=+1.50+0.010_{6} T \\
& Q_{\mathrm{Ga}(010)}^{*}=+0.52+0.001_{6} T \\
& Q_{\mathrm{Ga}(001)}^{*}=+1.86+0.010_{1} T
\end{aligned}
$$

It now appears that the Thomson coefficients for the $(100)$ and $(001)$ directions are approximately equal and much greater than the value for the (010) direction, which is rather small.

Further work with spectroscopically pure copper and lead has confirmed that the copper sample used in the earlier work was suitable as a reference standard. The absolute thermoelectric power of liquid gallium at $30^{\circ} \mathrm{C}$. has been found to be :

$$
Q_{G a(\text { liq.) }}^{*}=-0.2_{6} \mu \mathrm{V}, \text { deg. }^{-1} \mathrm{C} \text {. }
$$

This result confirms the belief of previous workers ${ }^{3}$, who deduced that the thermoelectric power of gallium was small, that there was a decrease of about one microvolt deg. ${ }^{-1} \mathrm{C}$. on melting and that probably this decrease was accompanied by a change of sign.

$$
\text { Physics Branch, }
$$

Royal Military College of Science,

Shrivenham, Swindon, Wiltshire.

${ }^{1}$ Horner, P., Nature, 191, 58 (1961).

${ }^{2}$ Stratton, R., Brit. J. App. Phys., 8, 315 (1957)

${ }^{3}$ Cusack, N., and Kendall, P., Proc. Phys. Soc., 75, 309 (1960).

\section{CHEMICAL ENGINEERING}

\section{Separations in Fluidized Systems by Means of Dielectric Charging of Materials}

ELSEWHERE ${ }^{1,2}$, we have described a new phenomenon, namely, that during the fluidization of solid materials in a gas stream under certain conditions charging of the particles occurs. We have also suggested that it is possible to separate components of a complex fluidized material, taking into account their physical and particularly dielectric properties.

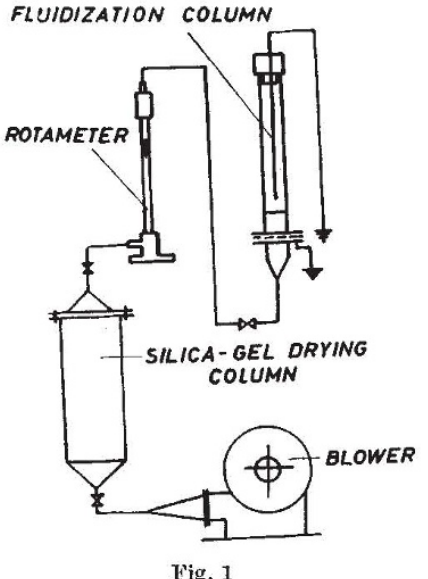

For examination of this phenomenon we used an arrangement shown in Fig. 1.

In order to effect the electrical charging, it is necessary that the material should be a non-conductor. If the moisture content of the gas is higher than a certain value, charging does not occur. If air is used, the relative moisture content should be about 30 per cent.

Owing to the vigorous movement inside the fluidization column, the particles collide with each other and with the walls of the column and acquire electrical charges. Presumably particles with different dielectric constants acquire different charges. On measuring the voltage of the metal rod submerged in the fluidized bed, we found that it varies with time and with the material used. At the beginning of the fluidization process, the voltage has its highest value, and varies from 400 to $5,000 \mathrm{~V}$. If a two-component system is being fluidized, and a metal rod, or a rod of some other material different from the walls of the column, is submerged in the fluidized bed, particles mainly of one component are separated on it. With a glass column and a metal rod, the walls of the column are charged positively and the metal rod negatively; this effect can be emphasized by earthing the metal rod. In relation to the depth of submergence of the rod in the fluidized bed, that is, to the distance from the rod tip to the wire net, the material separates in two places on the rod, the lower accumulation being of higher purity (Figs. 2 and 3). This is thought to be the result of very complex electrostatic fields in a system of this kind.

Table 1 System
Powdered iron-quartz Degree of Metal rod Glass wall of the Mand Magnetite-marble Coke-quartz sand Pyrite-quartz sand Pyrite-marble

Pyrhotine-quartz sand Pyrhotine-marble Barite-quartz sand
Barite-marble Hæmatite-quartz sand Hæmatite-marble Marble-quartz sand Hard coal-quartz sand high Hard coal-marble Brown coal-quartz sand high Brown coal-marble Lignite-quartz sand Lignite-marble Lignite-mar separation fluidization column none

very poor pyrite quartz sand and marble, respectively very poor pyrhotine quartz sand and fair barite marble, respectively quartz sand and fair hæmatite quartz sand and marble, respectively marble quartz sand hard coal quartz sand and marble, respectively brown coal quartz sand and marble, respectively quartz sand, marble quartz sand, marble
and clay, respec- very good lignite 